\title{
PENGARUH MODUL TEMATIK INQUIRY-DISCOVERY TERHADAP HASIL BELAJAR SISWA MATERI METABOLISME PEMBENTUK BIOENERGI
}

\author{
Sekar Dwi Ardianti \\ Program Studi Pendidikan Guru Sekolah Dasar \\ Fakultas Keguruan dan Ilmu Pendidikan \\ Email: sekardwiardianti@ymail.com
}

\begin{abstract}
The purpose of this study was to evaluate the influence of the thematic inquiry-discovery module on metabolism forming bioenergy student learning outcomes. This study is an experimental research with post test control group design conducted in class VII at SMP N 1 Sluke. Population in this research were all seventh grade students at SMP Negeri 1 Sluke. Cluster random sampling was implemented to devide samples into two groups as experimental group and control group. The independent variables in this study are the type of study material and dependent variable is the learning outcomes of students. The average of post test score in experimental group is 82.10 and 71.47 for control group. The average of psychomotoric score in experimental group is 75.8 and 64.0 for control group. The average of affective score in experimental group is 18.23 and 16.89 for control group.The $t$ - test results showed that the thematic inquiry-discovery module give real effect on learning outcomes (cognitive, psychomotoric, and affective aspects) on metabolism forming bioenergy.
\end{abstract}

Kata Kunci: thematic module, inquiry-discovery learning, metabolism

\begin{abstract}
ABSTRAK
Tujuan dari penelitian ini mengkaji pengaruh modul tematik inquiry-discovery terhadap hasil belajar siswa materi metabolisme pembentuk bioenergi. Penelitian ini merupakan penelitian eksperimen dengan post test control group design yang dilaksanakan pada siswa kelas VII SMPN 1 Sluke. Populasi dalam penelitian ini adalah seluruh siswa kelas VII SMP Negeri 1 Sluke. Pengambilan sampel menggunakan teknik cluster random sampling dengan jumlah sampel 2 kelas sebagai kelompok eksperimen dan kelompok konrol. Variabel bebas dalam penelitian ini adalah jenis bahan ajar serta variabel terikatnya adalah hasil belajar siswa. Rata-rata skor post-test siswa kelompok ekperimen mencapai 82,10 dan kelompok kontrol mencapai 71,47. Rata-rata skor psikomotorik siswa kelompok ekperimen mencapai 75,8 dan kelompok kontrol mencapai 64,0. Rata-rata skor minat dan sikap siswa kelompok ekperimen mencapai 18,23 dan kelompok kontrol mencapai 16,89. Hasil analisis uji-t menunjukkan modul tematik inquiry-discovery berpengaruh nyata terhadap hasil belajar (kognitif, psikomotorik, dan afektif) siswa materi metabolisme pembentuk bioenergi.
\end{abstract}

Kata kunci: modul tematik, inquiry-discovery, materi metabolisme pembentuk bioenergi.

\section{PENDAHULUAN}

Kurikulum 2013 mengamanatkan pembelajaran tematik dan terpadu. Hal tersebut tertuang jelas dalam Peraturan Menteri Pendidikan dan Kebudayaan (Permendikbud) Nomor 65 Tahun 2013 tentang standar proses Kurikulum 2013. Makna terpadu dalam pembelajaran IPA adalah keterkaitan antar beberapa kompetensi dasar suatu mata pelajaran yang melahirkan satu atau beberapa tema pembelajaran. Pembelajaran terpadu juga dikatakan sebagai pembelajaran yang memadukan materi beberapa mata pelajaran atau kajian ilmu dalam satu tema. Keterpaduan dalam pembelajaran IPA dimaksudkan agar pembelajaran IPA lebih bermakna, efektif, dan efisien. Keterpaduan tersebut dapat tertuang salah satunya melalui modul yang digunakan dalam pembelajaran.

Pembelajaran IPA berkaitan dengan cara mencari tahu tentang alam secara sistematis, sehingga IPA bukan hanya penguasaan kumpulan pengetahuan yang berupa fakta, konsep, atau prinsip saja tetapi 
juga merupakan proses penemuan. Pembelajaran inquiry adalah suatu proses belajar yang memberikan kesempatan siswa untuk menguji dan menafsirkan suatu permasalahan secara sistematika yang memberikan konklusi berdasarkan pembuktian. Prinsip pembelajaran inquiry tidak berbeda jauh dengan pembelajaran discovery. Rohmawati (2008) dalam penelitiannya di SMPN 1 Maduran Lamongan dengan sampel sebanyak 33 siswa menyatakan pembelajaran IPA akan lebih bermakna jika siswa diberi kesempatan untuk tahu dan terlibat aktif dalam menemukan konsep dari fakta-fakta yang dilihat dari lingkungan dengan bimbingan guru. Praptiwi (2012) dalam penelitiannya dengan metode eksperimen di SMP 21 Semarang menyatakan pembelajaran berbasis inquiry dipadukan dengan metode eksperimen dapat merangsang siswa aktif dan memberikan fasilitas untuk mengembangkan ketrampilan proses sains. Friedman et al. (2010) menegaskan bahwa pembelajaran berbasis inkuiri terkait dengan hakikat IPA sebagai proses inkuiri manusia dan mampu meningkatkan pencapaian hasil belajar siswa. Towndrow (2008) juga menyatakan bahwa ketika siswa memiliki kemampuan dan memahami inquiry, mereka akan lebih baik dalam mempersiapkan pembelajaran IPA. Pada pembelajaran inkuiri, siswa memegang peran dominan sehingga diharapkan inkuiri sebagai model pembelajaran yang ada dalam setiap pembelajaran IPA. Penggunaan inqury dalam pembelajaran IPA akan meningkatkan keterlibatan siswa dalam pembelajaran.

Hasil observasi menunjukkan bahwa konsep metabolisme pembentuk bioenergi di SMPN 1 Sluke selama ini disampaikan dengan metode ceramah dan didukung dengan bahan ajar yang konvensional. Bahan ajar yang digunakan sebagai sumber belajar siswa berupa buku teks yang menyajikan teori-teori dengan penyajian yang kurang menarik serta sedikit kegiatan yang melibatkan siswa aktif. Hal ini menyebabkan siswa hanya pandai untuk menghafal teori tanpa dapat memahami materi secara utuh. Hal ini dapat diketahui dari hasil belajar siswa yang masih rendah. Rata-rata kelas hanya sebesar 61,22 yang lebih rendah dari KKM sekolah sebesar 70,00.

Menurut Trianto (2010) keberhasilan pembelajaran sangat bergantung pada penggunaan sumber belajar maupun bahan ajar yang dipilih. Bahan ajar yang berkualitas terkait langsung dengan kualitas pembelajaran. Modul merupakan bahan ajar yang dikemas secara utuh dan sistematis untuk membantu siswa dalam mencapai tujuan pembelajaran secara mandiri maupun kelompok (Daryanto, 2013). Menurut Asfiah (2013) pembelajaran menggunakan modul menuntut siswa untuk belajar mandiri sehingga siswa terlibat aktif dalam pembelajaran.

Modul tematik menurut Izzati (2013) merupakan modul yang membahas sebuah tema pokok yang di dalamnya terdiri dari beberapa subtema. Modul tematik inquiry-discovery dalam penelitian ini merupakan bahan ajar mandiri dengan menggunakan tema yang mengikat KI, KD, dan mata pelajaran menjadi satu kesatuan utuh dengan menerapkan sintaks pembelajaran kerja ilmiah. Sintaks pembelajaran inquiry-discovery merupakan penggabungan dari inquiry dan discovery. Sintaks inquiry-discovery meliputi stimulasi, perumusan masalah, pengumpulan data, pengolahan data, pengujian hipotesis, menarik kesimpulan, dan evaluasi.

Tahap stimulasi menghadapkan siswa pada sesuatu yang menimbulkan kebingungan dan tidak diberikan generalisasi agar timbul keinginan untuk menyelidiki sendiri. Stimulasi ini berfungsi untuk menyediakan kondisi interaksi belajar yang dapat mengembangkan dan membantu siswa mengeksplorasi bahan. Menurut Illahi (2012) kegiatan menstimulasi sangat penting untuk diaktualisasikan karena mempunyai pengaruh yang besar yaitu dapat mengoptimalisasi ketrampilan siswa dalam bentuk nyata. Pemberian stimulasi dapat menggunakan sebuah pertanyaan atau sebuah kasus yang menimbulkan sebuah pertanyaan. Setelah dilakukan stimulasi siswa mengidentifikasi dan menganalisa permasalahan yang mereka hadapi serta menyusun hipotesis atau sebuah dugaan sementara untuk permasalahan tersebut. Tahap selanjutnya adalah pengumpulan data dimana siswa mengumpulkan informasi sebanyakbanyaknya yang relevan untuk membuktikan benar atau tidaknya hipotesis. Pengumpulan data dapat dilakukan dengan membaca literatur, pengamatan objek, wawancara, atau percobaan secara langsung. Data yang diperoleh kemudian diolah pada tahap pengolahan data. Siswa mengolah data dan informasi yang telah diperoleh baik melalui observasi, praktikum ataupun wawancara kemudian ditafsirkan. Semua informai hasil bacaan, wawancara, observasi, dan sebagainya, semuanya diolah, diacak, diklasifikasikan, ditabulasi, bahkan bila perlu dihitung dengan cara tertentu serta 
ditafsirkan. Kegiatan ini akan berujung pada generalisasi yang akan menghasilkan pengetahuan baru bagi siswa.

Kegiatan yang dilakukan siswa selanjutnya adalah pengujian hipotesis. Siswa melakukan pemeriksaan secara cermat untuk membuktikan benar atau tidaknya hipotesis yang ditetapkan dengan temuan alternatif dan dihubungkan dengan hasil pengolahan data pada tahap sebelumnya. Selanjutnya tahap menarik kesimpulan merupakan proses menarik kesimpulan yang dapat dijadikan prinsip umum yang berlaku untuk semua kejadian atau masalah yang sama dengan memperhatikan hasil. Tahap terakhir dari sintaks inquirydiscovery adalah evaluasi. Siswa menyampaikan kesimpulannya dan kembali melakukan pengkajian ulang atau evaluasi bersama teman, guru ataupun pembimbing.

Modul tematik inquiry-discovery merupakan modul yang penyajiannya disertai dengan kegiatan-kegiatan yang mengajak siswa untuk melakukan sebuah pengamatan dan penemuan dalam satu kesatuan yang utuh. Menurut Indrawan (2013) kegiatan pengamatan dan menemukan yang disertakan dalam pembelajaran akan mempermudah pemahaman siswa terhadap materi serta dapat mengurangi kejenuhan siswa dalam belajar. Modul tematik inquiry-discovery melatih siswa untuk mampu menemukan konsep-konsep baru berdasarkan kegiatan serta uraian singkat yang terdapat di dalamnya. Inovasi dalam modul tematik inquiry-discovery ini dapat membantu siswa mengatasi kesulitan tersebut, terutama dalam memahami materi metabolisme pembentuk bioenergi. Pembelajaran dengan modul tematik inquiry-discovery efektif dalam penyampaian pesan pembelajaran, karena mampu mengajak siswa aktif dan menjadikan pembelajaran bermakna. Penggunaan modul tematik inquirydiscovery diharapkan mampu meningkatkan aktivitas dan pemahaman siswa yang berdampak pada hasil belajar yang meningkat sehingga memperlancar proses pencapaian tujuan pembelajaran.
Penelitian ini bertujuan untuk mengkaji pengaruh penggunaan modul tematik inquirydiscovery terhadap hasil belajar siswa materi metabolisme pembentuk bioenergi di SMP N 1 Sluke Rembang.

\section{METODE PENELITIAN}

Penelitian ini dilaksanakan di SMP N 1 Sluke Rembang semester genap. Penelitian ini merupakan penelitian eksperimen dengan desain Post Test Control Group. Sampel yang digunakan adalah siswa kelas VII dari dua kelas yang diambil dari lima kelas secara Cluster Random Sampling. Kelas VIIE sebagai kelas eksperimen diberikan pembelajaran dengan menggunakan modul tematik inquirydiscovery sedangkan kelas VIID sebagai kelas kontrol diberikan pembelajaran dengan menggunakan bahan ajar IPA yang digunakan di SMP N Sluke Rembang.

Penelitian ini terdiri dari tiga variabel yaitu variabel bebas, variable terikat dan variabel kendali. Variabel bebas dalam penelitian ini adalah jenis bahan ajar yang meliputi modul tematik inquiry-discovery dan bahan ajar yang digunakan di sekolah. Variabel terikat dalam penelitian ini adalah hasil belajar materi metabolisme pembentuk bioenergi.

Data yang diamati adalah hasil belajar meliputi kognitif, psikomotorik, dan afektif. Data hasil belajar kognitif siswa diambil melalui skor post-test dengan tes pilihan ganda. Data hasil belajar psikomotorik siswa diambil melalui lembar observasi kegiatan praktikum dan data hasil belajar afektif siswa diambil melalui lembar observasi sikap dan minat siswa dalam pembelajaran. Data yang diperoleh kemudian dianalisis dengan dengan uji statistik parametrik Independent-Sample $T$ Test.

\section{HASIL DAN PEMBAHASAN}

Hasil belajar kognitif siswa diambil dari skor post-test materi metabolisme pembentuk bioenergi. Rekapitulasi hasil posttest materi metabolisme pembentuk bioenergi seperti pada Tabel 1.

Tabel 1. Rekapitulasi hasil post-test siswa kelompok eksperimen dan kontrol.

\begin{tabular}{lcc}
\hline \multirow{2}{*}{ Komponen } & \multicolumn{2}{c}{ Nilai Post-test } \\
\cline { 2 - 3 } & $\begin{array}{c}\text { Kelompok } \\
\text { Eksperimen }\end{array}$ & Kelompok Kontrol \\
\hline Rata-rata & 82,10 & 71,47 \\
Skor tertinggi & 83 & 93 \\
Skor terendah & 63 & 70 \\
\hline
\end{tabular}


Hasil perolehan skor post-test siswa menunjukkan bahwa secara umum siswa pada kelompok eksperimen mempunyai hasil belajar kognitif yang lebih tinggi dibandingkan dengan siswa pada kelompok kontrol. Hal tersebut dapat dilihat dari rata-rata skor post-test siswa kelompok ekperimen mencapai 82,10 dan kelompok kontrol mencapai 71,47 . Nilai posttest tersebut selanjutnya dianalisis secara statistik dengan uji-t. Uji-t dilakukan untuk mengetahui perbedaan hasil belajar kognitif siswa antara kelompok eksperimen dan kelompok kontrol. Berdasarkan perhitungan diperoleh nilai $t_{\text {-hitung }}$ sebesar 7,722. Nilai $t_{\text {-hitung }}$ kemudian dibandingkan dengan nilai $t_{\text {-tabel }}$ dan hasilnya menunjukkan bahwa nilai $t_{\text {-hitung }} 7,722$ $>t_{\text {-tabel }}$ 2,001. Hal tersebut berarti bahwa terdapat perbedaan yang signifikan rata-rata skor post-test kelompok ekperimen dan kelompok kontrol.

Hasil belajar psikomotorik siswa diambil dari aktivitas siswa selama pembelajaran menggunakan lembar observasi. Rata-rata skor psikomotorik siswa antara kelompok eksperimen dan kelompok kontrol ditunjukkan pada Tabel

Tabel 2. Rekapitulasi skor psikomotorik siswa kelompok eksperimen dan kontrol

\begin{tabular}{lcc}
\hline \multicolumn{1}{c}{ Komponen } & \multicolumn{2}{c}{ Skor Psikomotorik } \\
\cline { 2 - 3 } & Kelompok Eksperimen & Kelompok Kontrol \\
\hline Rata-rata pertemuan 1 & 67,1 & 49,3 \\
Rata-rata pertemuan 2 & 71,3 & 65,3 \\
Rata-rata pertemuan 3 & 77,7 & 65,0 \\
Rata-rata pertemuan 4 & 87,1 & 76,3 \\
Rata-rata skor total & 75,8 & 64,0 \\
\hline
\end{tabular}

Hasil perolehan skor psikomotorik siswa menunjukkan bahwa secara umum siswa kelompok eksperimen mempunyai hasil belajar psikomotorik yang lebih tinggi dibandingkan dengan siswa kelompok kontrol. Hal tersebut dapat dilihat dari rata-rata skor psikomotorik siswa kelompok ekperimen mencapai 75,8 dan kelompok kontrol mencapai 64,0.

Skor psikomotorik tersebut selanjutnya dianalisis secara statistik dengan uji-t. Uji-t dilakukan untuk mengetahui perbedaan hasil skor psikomotorik siswa antara kelompok eksperimen dan kelompok kontrol. Berdasarkan perhitungan diperoleh nilai $t_{\text {-hitung }}$ sebesar 6,563. Nilai $t_{\text {-hitung }}$ kemudian dibandingkan dengan nilai $t_{\text {-tabel }}$ dan hasilnya menunjukkan bahwa nilai $t_{\text {-hitung }} 6,563>t_{\text {-tabel }} 2,001$. Hal tersebut berarti bahwa terdapat perbedaan yang signifikan rata-rata skor psikomotorik siswa kelompok ekperimen dan kelompok kontrol.

Hasil belajar afektif siswa diambil dari minat dan sikap siswa selama pembelajaran menggunakan lembar observasi. Rata-rata skor afektif siswa antara kelompok eksperimen dan kelompok kontrol disajikan pada Tabel 3.

Tabel 3. Rekapitulasi skor afektif siswa kelompok eksperimen dan kontrol

\begin{tabular}{lcc}
\hline \multicolumn{1}{c}{ Komponen } & \multicolumn{2}{c}{ Skor Afektif } \\
\cline { 2 - 3 } & Kelompok Eksperimen & Kelompok Kontrol \\
\hline Rata-rata pertemuan 1 & 18,42 & 17,17 \\
Rata-rata pertemuan 2 & 18,26 & 16,80 \\
Rata-rata pertemuan 3 & 18,35 & 17,03 \\
Rata-rata pertemuan 4 & 17,87 & 16,57 \\
Rata-rata skor total & 18,23 & 16,89 \\
\hline
\end{tabular}

Hasil perolehan skor menunjukkan bahwa secara umum siswa kelompok eksperimen mempunyai hasil belajar afektif yang lebih tinggi dibandingkan dengan siswa kelompok kontrol. Hal tersebut dapat dilihat dari rata-rata skor minat dan sikap siswa kelompok ekperimen mencapai 18,23 dan kelompok kontrol mencapai 16,89.

Skor afektif selanjutnya dianalisis secara statistik dengan uji-t. Uji-t dilakukan untuk mengetahui perbedaan skor afektif siswa antara kelompok eksperimen dan kelompok kontrol. Berdasarkan perhitungan diperoleh nilai $t_{\text {-hitung }}$ sebesar 3,028. Nilai $t_{\text {-hitung }}$ kemudian dibandingkan dengan nilai $t_{\text {-tabel }}$ dan hasilnya menunjukkan bahwa nilai $t_{\text {-hitung }} 3,028>t_{\text {tabel }}$ 2,001. Hal ini berarti bahwa terdapat perbedaan yang signifikan rata-rata skor afektif siswa kelompok ekperimen dengan kelompok kontrol. 
Hasil uji-t secara keseluruhan menunjukkan bahwa terdapat perbedaan signifikan antara kelompok ekperimen dengan kelompok kontrol baik pada hasil belajar kognitif, psikomotorik, dan afektifnya. Adanya perbedaan hasil belajar (kognitif. psikomotorik, dan afektif) antara kelompok eksperimen dan kelompok kontrol disebabkan karena penggunaan bahan ajar yang berbeda. Kelompok eksperimen menggunakan bahan ajar modul tematik inquiry-discovery sedangkan kelompok kontrol menggunakan bahan ajar yang digunakan di sekolah yaitu Buku Sekolah Elektronik ( BSE). Penggunaan inquiry yang diterapkan dalam modul pembelajaran merangsang siswa aktif mencari tahu dan menemukan dalam kegiatan pembelajaran. Keterlibatan siswa dalam kegiatan pembelajaran menjadikan terciptanya pembelajaran bermakna yang berdampak pada peningkatan hasil belajar. Ridwan (2013) menyatakan bahwa penerapan model pembelajaran inquiry pada tema pencemaran air menunjukkan peningkatan hasil belajar baik dari kognitif, afektif, dan psikomotorik. Guru juga merasakan peningkatan hasil belajar siswa karena siswa dapat memahami materi dengan menggunakan modul tematik inquiry-discovery. Konsep yang diterima siswa tidak hanya berupa hafalan namun aplikasi dalam kehidupan sehari-hari sehingga siswa akan memperoleh pembelajaran yang bermakna. Friedman et al. (2010) menyatakan bahwa pembelajaran inquiry dapat meningkatkan hasil belajar siswa karena siswa memegang peran dominan dalam pembelajaran. Kelompok eksperimen menggunakan bahan ajar modul tematik inquiry-discovery yang di dalamnya terdapat kegiatan mengajak siswa untuk melakukan pengamatan, pemecahan masalah dan penemuan konsep sendiri secara langsung. Kegiatan tersebut mempermudah siswa dalam memahami suatu materi pelajaran dan berdampak terhadap hasil belajar yang diperolehnya. Menurut Budiada (2011) melalui penerapan pembelajaran inquiry siswa mampu menemukan sendiri konsep materi pembelajaran dan menjadikan belajar siswa lebih bermakna. Kebermaknaan dalam belajar akan berdampak pada daya ingat serta pemahaman siswa terhadap konsep lebih kuat sehingga berdampak positif terhadap hasil belajar.

Siswa aktif menentukan topik, menentukan dugaan sementara, melakukan percobaan untuk memecahkan sebuah kasus dan menemukan konsep baru. Siswa mendapatkan pengalaman secara langsung melalui kegiatan percobaan yang dilakukan sehingga mampu menemukan pengetahuannya dengan sendirinya. Hal tersebut sesuai dengan pendapat Kristiyaningsih (2010) yang menyatakan bahwa pembelajaran dengan mengajak siswa aktif dalam percobaan sehingga siswa terlibat langsung pada materi dapat meningkatkan ketuntasan klasikal siswa. Estuningsih (2013) juga menyatakan bahwa pembelajaran dengan menggunakan LKS berbasis guided inquiry memberikan pengalaman langsung dan pembelajaran yang bermakna karena menggunakan pertanyaan yang terstruktur yang mengarahkan siswa sampai dapat menemukan suatu konsep. Pembelajaran tersebut akan memberikan pengalaman nyata dan bermakna bagi siswa sehingga konsep yang diterima siswa bukanlah sebagai konsep yang perlu dihafalkan. Hal ini sesuai dengan pendapat Justice (2009) bahwa inquiry dapat meningkatkan pembelajaran siswa dan kinerja siswa melalui kegiatan penyelidikan yang menarik bagi siswa. Pembelajaran dengan menerapkan desain inquiry dapat merangsang siswa aktif dalam kegiatan belajarnya. Hal tersebut juga didukung oleh Oliver (2008) yang menyatakan bahwa pembelajaran dengan menggunakan web berbasis inquiry meningkatkan keterlibatan siswa dalam pembelajaran karena harus melakukan berbagai macam penyelidikan.

Penggunaan modul tematik inquirydiscovery dalam pembelajaran materi metabolisme pembentuk bioenergi dapat meningkatkan hasil belajar baik kognitif, psikomotorik, dan afektif. Namun dalam pembelajaran menggunakan modul tematik inquiry-discovery diperlukan suatu perencanaan yang lebih matang dan pengelolaan waktu yang baik. Perencanaan dalam menyusun modul dan mempersiapkan beberapa alat dalam kegiatan praktikum perlu diperhatikan agar proses pembelajaran dapat berjalan sesuai dengan yang diharapkan. Hal inilah yang dirasakan guru sebagai kesulitan dalam proses pembelajaran. Namun, guru menyatakan ketertarikannya dalam menggunakan modul tematik inquirydiscovery karena mampu mengajak siswa aktif dan meningkatkan hasil belajar.

\section{SIMPULAN DAN SARAN}

\section{A. Simpulan}

Berdasarkan hasil penelitian diperoleh simpulan bahwa penggunaan modul tematik 
inquiry-discovery berpengaruh signifikans terhadap hasil belajar siswa pada materi metabolisme pembentuk bioenergi ditunjukkan dengan hasil uji-t skor post-test, skor psikomotorik, dan skor afektif menunjukkan nilai $t_{\text {-hitung }}>t_{\text {-tabel }}$.

\section{B. Saran}

Berdasarkan beberapa kendala yang ditemui dalam penelitian ini dapat disarankan sebagai berikut:
1. Untuk dapat menggunakan modul tematik inquiry-discovery sebagai bahan ajar dibutuhkan pranata laboratorium pendidikan (PLP) yang membantu guru menyiapkan dalam kegiatan praktikum.

2. Untuk penelitian selanjutnya dapat mengkaji pengaruh penggunaan modul tematik inquiry-discovery terhadap tingkat kreatifitas siswa karena tidak dapat terjangkau dalam penelitian ini.

\section{DAFTAR PUSTAKA}

Asfiah N, Mosik, \& Purwantoyo E. 2013. Pengembangan Modul IPA Terpadu Kontekstual pada Tema Bunyi. Unnes Science Education Journal. 2(1):188-195.

Budiada IW. 2011. Pengaruh Penerapan Model Pembelajaran Inquiry Terbimbing Berbasis Asesmen Portofolio Terhadap Hasil Belajar Kimia Siswa Kelas X Ditinjau dari Adversity Quotient. Jurnal Penelitian dan Evaluasi Pendidikan. 1(2).

Daryanto. 2013. Menyusun Modul. Yogyakarta: Gava Media.

Estuningsih S, Susantini E, \& Isnawati. 2013. Pengembangan Lembar Kerja Siswa (LKS) Berbasis Penemuan Terbimbing (Guided Discovery) untuk Meningkatkan Hasil Belajar Peserta Didik Kelas XII IPA SMA Pada Materi Substansi Genetika. Jurnal Bioedu. 2(1): 27-30.

Friedman DB, Crews TB, Caicedo JM, Besley JC, Weinberg J, \& Freeman ML. 2010. An Exploration into Inquiry-Based Learning by A Multidisciplinary Group of Higher Education Faculty. Springer High Education. 59:765-783.

Illahi MT. 2012. Pembelajaran Discovery Strategy \& Mental Vacational Skill. Yogyakarta: Diva Press.

Indrawan MI, Suharsono N, \& Tegeh MI. 2013. Pengembangan Multimedia Interaktif Berbasis Inquiry untuk Pembelajaran Komputer Grafis Siswa Desain Komunikasi Visual di SMK. Jurnal teknologi Pembelajaran. 3: 67-72.

Izzati N, Hindarto N, \& Pamelasari SD. 2013. Pengembangan Modul Tematik dan Inovatif Berkarakter pada Tema Pencemaran Lingkungan untuk Siswa Kelas VII SMP. Jurnal Pendidikan IPA Indonesia. 2(2): 183-188.

Justice C, Rice J, Roy D, Hudspith B, \& Jenkins H. 2009. Inquiry Based Learning in Higher Education: Administrators Perspectives on Integrating Inquiry Pedagogy into The Curriculum. Springer Journal High Education. 58:841-855.

Kristianingsih DD, Sukiswo SE, \& Khanafiyah S. 2010. Peningkatan Hasil Belajar Siswa melalui Model Pembelajaran Inquiry dengan Metode Pictoral Riddle pada Pokok Bahasan Alat-Alat Optik di SMP. Jurnal Pendidikan Fisika Indonesia. 6 :10-13.

Oliver R. 2008. Engaging First Year Student Using A Web-Supported Inquiry Based Learning Setting. Spinger Journal High Education. 55:55-301.

Permendikbud Nomor 65 Tahun 2013 tentang Standar Proses.

Praptiwi L, Sarwi, \& Handyani L. 2012. Efektifitas Model Pembelajaran Eksperiment Inquiry Terbimbing Berbantuan My Own Dictionary untuk Meningkatkan Penguasaan Konsep dan Unjuk Kerja Siswa SMP RSBI. Unnes Science Education Journal. 1(2):86-95.

Ridwan A, Susantini E, \& Maulida NA. 2013. Penerapan Model pembelajaran Inkuiri pada Tema Pencemaran Air untuk Meningkatkan Ketuntasan Hasil Belajar Siswa di Kelas VII SMP Negeri 2 Buduran Sidoarjo. Jurnal Pendidikan Sains E-Pensa. 1 (1):13-17.

Rohmawati AN. 2008. Penerapan Pembelajaran IPA Terpadu dengan Model Pembelajaran Inquiry pada Tema Mata di SMP Negeri 1 Maduran Lamongan. PENSA E-Journal. 76-91.

Towndrow PA, \& Ling TA. 2008. Promoting Inquiry Through Science Reflective Journal Writing. Eurasia Journal of Mathematics, Science and Technology Education. 4 (3): 279-283

Trianto. 2010. Model Pembelajaran Terpadu: Konsep, Strategi dan Implementasinya dalam KTSP. Jakarta: Bumi Aksara. 